\title{
Clinical Trial Oversight Committee Information
}

National Cancer Institute

\section{Source}

National Cancer Institute. Clinical Trial Oversight Committee Information. NCI Thesaurus.

Code C115556.

Documentation pertaining to the organization that approves, monitors, and reviews

biomedical research to protect the rights, safety and welfare of the study subjects. 